ISSN: 2162-3104 Print/ ISSN: 2166-3750 Online

Volume 8, Issue 3 (2018), pp. 1408-1421

(C) Journal of International Students

http://jistudents.org/

doi: $10.5281 /$ zenodo. 1254603

\title{
Community, Identity, and International Student Engagement
}

\author{
Michelle Metro-Roland \\ Western Michigan University, USA
}

\begin{abstract}
This article explores the insights of cosmopolitanism as they relate to questions of international student inclusion. Enacting policies and practices that highlight a rooted cosmopolitanism, one where particular attachments are partially constitutive of identity, offers one way to successfully foster inclusion. Membership in particular communities need not stand as an obstacle to engaging; instead, values provide not a barrier but a means by which intercultural engagement can occur. One approach is to create communities organized around shared markers beyond national identity alone. This article illustrates this by highlighting the process of organizing a diverse group of international students in order to create a sense of community, a home base, so to speak, which served to foster both a sense of belonging and further social engagement with the university community.
\end{abstract}

Keywords: international student inclusion, cosmopolitanism, identity, engagement

Student mobility is often viewed as the hallmark of internationalization. US universities send their domestic students abroad and serve as host to students from around the globe, in ESL programs, non-degree exchanges, and undergraduate and graduate degree programs. The number of international students on US campuses is seen as a relevant marker of a college or university's global engagement. Those working in international education know that mobility, getting students moved from one place to another, is only part of the story. So too is the knowledge transfer that takes place. While we want students to learn in the classroom and learn their disciplines in different ways, what we really hope for is that these international 
educational experiences will change perceptions. The reason d'être of the US Department of State's Bureau of Educational and Cultural Affairs underscores this idea that educational exchange effects real change, leading those who venture abroad to better understand others ("Bureau of Education," n.d.). But we know that simple dislocation is not causation; in other words, just being abroad does not lead, ipso facto, to more openmindedness or understanding.

As international student populations have grown, universities have had to look more closely at questions of inclusion, and how international students are acclimating, and being acclimated, to the social, cultural, and academic norms in their host countries and communities. We know that students do better when they feel a sense of belonging, whether they are domestic or international. There are a number of ways to foster inclusion. This article looks at the question of inclusion by highlighting the complexities of identity in relation to belonging. After a discussion of cosmopolitanism and identity, the article offers a view into how creating conditions that allow for a multiplicity of identities for international students might foster a sense of belonging and social engagement.

\section{BACKGROUND}

In international education, the goal is often stated as developing students who are interculturally competent, but what does that mean? Deardoff's (2010) research on intercultural competency highlights three key areas: attitudes, knowledge, and skills. Attitudes relate to "respect, openness, curiosity and discovery" towards and about others (p. 1). Knowledge includes "cultural self-awareness (meaning the ways in which one's culture has influenced one's identity and worldview), culture-specific knowledge, deep cultural knowledge including understanding other world views, and sociolinguistic awareness" (p. 1). And skills refer to "the acquisition and processing of knowledge: observation, listening, evaluating, analyzing, interpreting, and relating" (p. 1). However, the idea of cultural competency, that someone can become an expert in another culture, has also been questioned. The concept of cultural "humility and not so much the discrete mastery traditionally implied by the static notion of competence" has been proposed as an alternative (Tervalon \& Murray-Garcia, 1998, p. 120). Both ultimately aim at understanding, but they start from different places.

The question that one may ask though is why is inter-cultural competency or humility important? One could offer an instrumentalist view that we have a heightened shrinking of space and time, and we are indelibly interconnected to what happens over the horizon and beyond our borders. 
Globalization has been defined as "the increasing interconnectedness of different parts of the world through common processes of economic, political and cultural change" (Marston et al., 2002, p. 10). Manfred Steger (2003) argues that globalization is a "multidimensional set of social processes that create, multiply, stretch and intensify worldwide social interdependencies and exchanges while fostering in people a growing awareness of deepening connections between the local and the distant" (p. 13). Although there is some debate about when we became global (i.e., whether this is a wholly new phenomenon), it seems more persuasive to say that we have been global far longer than we have been provincial (Ritzer, 2010). Wherever one comes down on this debate, it makes sense to think about this as a question of scale and scope.

In order to succeed in a globalized world, an international education can give one an advantage. Macready and Tucker (2011) note that one of the push factors for international education abroad is the market. They cite arguments from the OECD that, "Globally oriented firms seek internationally-competent workers who speak foreign languages and have the intercultural skills needed to successfully interact with international partners. Governments as well as individuals are looking to higher education to broaden students' horizons and help them to understand the world's languages, cultures and business methods" (p. 42). Many times, when students are making the argument for pursuing an international education they note that "it will look good on a resume," thus invoking a crass instrumentalist view. It is not simply the line on the resume but what it signifies. It is because of what happens, what one gains in pursuing an international education in a foreign setting, that matters.

A more salient argument for why it is important to attend to intercultural concerns is the intrinsic argument of what this does for you not as a member of the marketplace but as a member of society. One way to think about this is through the lens of cosmopolitanism. Martha Nussbaum (1994) contends that "[i]f we [Americans] really do believe that all human beings are created equal and endowed with certain unalienable rights, we are morally required to think about what that conception requires us to do with and for the rest of the world" (p. 7). Students, she argues, should "be taught that while they themselves happen to be situated in the Unites States, they have to share this world of human beings with the citizens of other countries" (1994, p. 3).

This cleaving to identity is a pervasive need of creating a sense of belonging. Amin Maalouf (2000), the French, Lebanese, Arab, Christian, Melchite novelist speaks of murderous or mortal identities. The idea of belonging can reduce identity to "one single affiliation-encourag[ing] 
people to adopt an attitude that is partial, sectarian, intolerant, domineering, sometimes suicidal, and frequently even changes them into killers or supporters of killers" (p. 30). The reality is that identity is multifarious, scaled and shifting, and if we follow Maalouf, by allowing our identities to be fluid, we can find common ground with others across boundaries and borders, across the chasms that seem deep and impassable. In many cases, it is dislocation in space that can evoke this attitude. We want to create belonging, and even in the smallest of places, we begin to create distinctions between "us" and "them." The things which we find to create that division between "us" and "them" is context dependent. By immersing ourselves in a new environment, we can break down perceived barriers.

The humanistic geographer Yi-Fu Tuan (1977) has written extensively on our perceptions of our physical environment, noting that obvious physical signs are not good indicators of the ways in which we conceptualize the spaces around us. One way to see this is his focus on perceptions of crowding, where he notes that paradoxically we may feel crowded in the confines of a small town where everyone is in our business, but the anonymous teeming crowds of the big city allow us to breath more freely. These perceptions of space allow us to find connections with others when we are removed from our normal spaces. On many college campuses, it is not unusual to see hundreds of other people each day wearing shirts or hoodies embellished with the school's logo. It is a commonality. And one remains almost unaware of its frequency. But imagine being thousands of miles away on another continent and finding a stranger wearing your school colors. You may feel a sudden sense of kinship and may reach out to acknowledge your mutually shared identity in spite of your not knowing one another and perhaps having nothing more in common than that tenuous shared hoodie.

Spatial and social context matters for the exercise and privileging of the various facets of our identity. Ulrich Beck (2006) contends that we need a "nonlinear, dialectical process, in which the universal and the particular, the similar and the dissimilar, the global and the local, are to be conceived, not as cultural polarities, but as interconnected and reciprocally interpenetrating principles" (pp. 72-73). The best way to do this is to ensure that there is an interweaving of the local and the global, that the similar and dissimilar can bounce up against one another and interact, that the dissimilar can be made familiar. For international and domestic students, the differences in national identity should coexist with the similarities of being a foodie, or a footballer, and not overtake these other identities.

To go back to Nussbaum (1994), in her diagnosis for US students, she notes that in order to adopt a disposition of cosmopolitanism, students 
should both learn about their own culture and traditions, but they also need to "learn a great deal more than is frequently the case about the rest of the world in which they live, about India and Bolivia and Nigeria and Norway and their histories, problems, and comparative successes" (p. 2). In the context of the internationalized university, this learning takes place not just in the classroom but in the social and cultural life of the campus. But it does not happen passively. It requires effort to create the context for such learning to take place, and we must attend to the expectations of international students.

In studying abroad, students face the dilemma of interacting with people and places that do not lend themselves to the sense of well-being one can find at home. Part of the tension here goes back to this issue of identity - of wanting to feel a sense of belonging. For many international students studying in the US, especially for those coming from more communal rather than individualistic cultures, the experience can be alienating. Studies dealing with social integration of international students highlight the misperceptions that arise as international students are drawn to each other, and domestic students then see this clustering as itself alienating. However, research on integration has shown that,

international students most engaged in activities and events
sponsored by their own culture are also most likely to also be
engaged with events sponsored by cultures different from their
own. Own culture events help develop a strong social network
with co-national peers as international students explore an
unfamiliar cultural environment, including forming friendships
with U.S. students and international students from other
countries. (Glass, Buss, \& Brasskamp, 2013, p. 13)

In their comprehensive study of nearly 2,000 international students and just over 35,000 domestic students at 135 colleges and universities, Glass, Buss and Brasskamp (2013) highlighted this lack of belonging. The authors found that "[i]nternational students rate their sense of community significantly lower than their U.S. peers along every dimension, especially when asked whether they feel part of a close and supportive community of colleagues and friends at their institution" (p. 2).

These findings are echoed in the work of other researchers. In a notable qualitative study of 24 international students studying at a US institute in the Southwest, the authors found what they cite as disturbing stories about disrespect, prejudice, and exclusion from domestic students, faculty, and members of the larger community (Lee \& Rice, 2007). International students reported being ignored by classmates during group 
work, not being invited to social events, having disparaging comments about their perceived or actual cultural heritage lobbed at them, and exasperation by faculty as they struggled to be active participants in the student-centered classroom where discussion is prized. Equally troubling was the lack of interest of American students. As the authors write, "though perhaps unintentional, such indifference to other ways of life can marginalize anything not American, anything not understood. Such apathy and unwillingness to attempt understanding translates to the rejection of international students' cultural identities" (Lee \& Rice, 2007, p. 19). This othering is problematic and stands to prevent the student from fully finding their place in their new adopted home. One student at our university perhaps best summed up the problem when they quipped that making friends with local students depends on your luck. Universities can try to maximize this luck by creating the conditions that will foster a sense of belonging for international students by creating an environment that allows for international students to explore their multiple identities.

In writing about how to cultivate a cosmopolitan attitude, the British-Ghanaian philosopher and novelist Kwame Appiah (2006) suggests that we "should learn about people in other places, take an interest in their civilizations, their arguments, their errors, their achievements, not because that will bring us to agreement, but because it will help us get used to one another" (p. 78). There are many ways to approach the idea of cultural competency/cultural humility. Appiah's idea of "getting used to one another" is an appealing summation of what to hope for in its approximation of what happens when we forge relationships. Getting used to one another, though, will not simply happen by being proximate to one another. It will not happen by simply saying "hey" in class twice a week. It will only happen when we stop and open up, when we engage, when we risk ourselves in conversation and in friendship, when we work towards a common task, when we move out of bubbles. One way to do this is to find a common ground on which to meet that transcends national identity. What follows is a description of one attempt to create community for international students based on shared markers unlinked to shared citizenship but one which allowed for students' cultural identities to be recognized.

\section{THE FULBRIGHT EXPERIENCE: AN EXAMPLE OF INTERNATIONAL COMMUNITY BUILDING}

Western Michigan University is a mid-sized, comprehensive university with approximately 24,000 students, located in the town of Kalamazoo, Michigan. There are around 1,800 international students from almost 100 
countries, the largest groups coming from Saudi Arabia, India, and China. Global Engagement is one of three stated pillars of the university and international issues are handled by a centralized office, the Haenicke Institute for Global Education, headed by an associate provost. The Institute houses international admissions and student services, an ESL program, study abroad, an office of international student activities, immigration, scholar services, and works in cooperation with other units to promote comprehensive internationalization across campus.

Several years ago, the university administration made Fulbright a priority, centralizing the responsibility for the Fulbright US and Foreign Scholar and Student programs in the Haenicke Institute under the author's responsibility, and putting financial resources towards support for foreign Fulbright students. In the 2016-2017 academic year, the university was recognized by the Chronicle of Higher Education (2017) as being a top producer of Fulbright Scholars among research universities. Since 2009, the university has seen an increase in the number of Fulbright Foreign Students coming to do graduate work, going from single digits to over 40 fellows in 2017-18. The diversity of programs in which Fulbright foreign students have been enrolled has expanded to include graduate programs from five of the major colleges. The breath of countries from which fellows come also expanded to nearly two dozen. This diversity among students offered opportunities and challenges. As part of the efforts to support this expanding population, the author's role as the Fulbright Foreign Student Advisor (FSA) was also expanded to provide support for students in addition to that mandated by the Fulbright program.

This work took two parallel paths: first, creating the context and infrastructure at the institutional level for Fulbright foreign students to be supported, and second, encouraging the students to organize themselves into an official group, which is referred to as a Registered Student Organization (RSO). The ultimate goal has been to create a sense of community and belonging that would allow students to flourish, academically and socially. Each of these paths will be discussed in turn.

The university, which has been hosting foreign students since almost its opening in 1903, already had a structure in place for international students through the Haenicke Institute. These included the office of International Admissions and Student Services (IAS), International Student Activities (ISA), and the International Student Advocate. The admissions office, which also houses immigration, holds drop-in and appointment-based advising hours for students during the week to address problems or questions they may have about visa status, Optional Practical Training, reduced course loads, etc. The International Student Advocate handles 
problem cases such as medical emergencies, or students who have found themselves in serious academic or financial trouble. This position works closely with Student Affairs and other units across campus to assist students in crisis, mobilizing resources, and offering insight on the specific aspects unique to international students, such as immigration implications. ISA offers year-round cultural and social activities for students, such as trips to local attractions, seasonal dances, and the international festival showcase. It also organizes orientation for incoming international students.

As we looked to create community for the Fulbright students, there were several nodes we identified: pre-arrival, orientation, the academic year, and graduation. Once confirmation of placement was received, Fulbright students were sent a welcome letter with details about housing, orientation, local transportation, and arrival. Much of this information was similar to what the general international student population was receiving with two exceptions. The letter included the names and emails of enrolled Fulbright students who had volunteered to be "Welcome Ambassadors" along with the email and cell number for the FSA. It also included invitations to social media, specifically the closed WMU Fulbright group on Facebook. Through these resources, newly admitted students were able to pose questions to continuing students about the university or the town, inquiries about things like housing options, cold weather clothing, academic programs, etc. These ambassadors and the members of the Facebook group were also instrumental in hosting or arranging temporary accommodations for newlyarrived students before their official apartments were ready. The Facebook group also allows for incoming students to meet each other and to arrange to room together.

The next step in creating a sense of belonging was holding a series of Fulbright specific events during orientation. Over 400 students attend the Fall orientation annually, and one of the goals has been to create more differentiated experiences for these students by creating smaller interest groups. The Fulbright experience is one way of doing this. These students are assigned to a larger orientation group made up of graduate students and attend the regular sessions, but they also attend two events that are Fulbright only. The first is a special Fulbright Orientation session with the FSA. There are several goals for the session. First, new students get the opportunity to meet each other in person. Second, administrative tasks such as explanations about how the Fulbright and the university insurance work are undertaken, and the Family Educational Rights and Privacy Act (FERPA) and student information and interest sheets are completed. Third, we discuss things like stress, study tips, where to go with specific concerns, work-life balance, etc. We also discuss the need to stay connected to one's home community but 
how it is also important to get involved in their new university community, and we talk about the Fulbright specific activities that are planned during the year (more below) through the Institute and the student organization. Students also receive a number of material items marking their belonging to the Fulbright group at WMU.

The following day during orientation the Fulbright lunch takes place with new and returning students. Along with the opportunity for students to get to know each other, returning students reconnect after the summer break. We have also used this event as a chance for returning students to offer tips and insights to new students, from where to buy hard-to-find grocery items, and how to handle the cold weather, to academic resources that are available on campus. The event is open to Fulbright "alumni" as well, including those students who have completed a Master's degree with Fulbright sponsorship and have continued into Doctoral programs. These students tend to have the most useful academic tips on handling the challenges of graduate school.

Early in the move to creating a sense of community amongst the Fulbright students, we recognized that it was important to offer a critical mass of activities early during the year in order to create numerous contact points. This would give students plenty of opportunity to become familiar with each other and to hopefully become comfortable in their new home. We have found that the familiarity of repetition, of seeing the same people, seems to help students who might be shy or uncomfortable in social situations. To this same end, we also make sure that we focus gatherings around activities and that we balance structure with the opportunity to have some down time for those students who might become tired from socializing. Two large events are interspersed with smaller activities. This also works with the academic calendar when course work is lighter at the start of the semester. Students travel to Grand Rapids for the day to attend Art Prize in September. This is a vast exhibition of art throughout the city. In October, after mid-terms, we travel to Chicago for a two-day visit. Depending on the year, the students visit the Art Institute or the Field Museum, and then have time to explore the city in smaller groups. Other activities during the Fall have varied. Students have gone apple picking at a local farm and we have organized a football tail-gate. We also participate in some of the Fulbright Association Michigan Chapter events, including the Welcome Party that takes place in December.

The spring semester features two major celebratory events. In February, the Haenicke Institute hosts the annual Fulbright Reception. Faculty and student alumni, Fulbright foreign students, the President, Provost, Deans, faculty mentors, and others who are friends of the program attend the event which is held in the university art museum and features a 
student jazz band, speeches, and the chance for students to meet with the president. It has become a highly visible way to recognize the achievements of students and faculty. The other event, held in coordination with the Fulbright Student Organization (FSO), is the Graduation Celebration in April. Soon to be alumni are given the opportunity to speak at the ceremony and reflect on their experiences, and they are again presented with material items marking their belonging with Fulbright at WMU.

The idea to organize students into an official recognized student group came from a colleague at Eastern Michigan University. When we reached out to the then Fulbright students on campus, one of the selling points was the opportunity for them to gain leadership experience and to access university resources that would allow them to organize student-led events. There was also an ancillary benefit for our particular students that became apparent once the organization was up and holding its first elections. A large proportion of our Fulbright students come from emerging democracies. During the inaugural meeting, prior to voting, students were asked by the interim president to tell about their experiences with democracy and with voting. For some students, this was their first time participating in an election and they spoke movingly about what this meant for them. The running for positions within the leadership structure also served as a mini-lesson in the art of persuasion and campaigning. The early rounds of the FSO experimented in radical democracy, holding multiple elections several times throughout the year in order to share power widely. As new students entered the FSO, elections were standardized to once per year.

Each of the executive boards and the groups themselves have set their own priorities. Some groups have focused on community engagement and volunteering. Other groups have focused on cultural sharing, hosting specific nights dedicated to the food, history, and culture of their home countries. These have been especially interesting when students share a nationality but come from different ethnic groups. These culture nights are open to the larger community, and friends from both inside the university and the town have attended. The FSO has also participated in the annual International Festival, sponsored by International Student Activities. The event, which brings together international RSOs, offers groups a showcase for their culture. The student groups host a booth that highlights material culture artifacts and work with dining services to cook up to four dishes from their home countries. There is also a fashion show and dance performances. Most RSOs are specific to one country and will offer regional and ethnic variations in their costumes and performances. The FSO has taken up participation in the festival over the last several years and has 
performed dances from close to a dozen different countries, and offered an eclectic mix of foods from around the globe.

\section{DISCUSSION AND CONCLUSIONS}

Fulbright students have, to use Appiah's (2006) phrase, learned "to get used to one another" (p. 78). In preparing for the festival, they have had to find ways to make choices about which of the nearly two dozen countries they will highlight. They have had to negotiate vastly different spatial proxemics as they learned dance moves from across the globe, from Latin America to the Middle East. In their meetings and in the Institute-sponsored activities that they attend, they have had to sit next to students from neighboring countries and other ethnic or sectarian groups within their home countries and have had to get over any biases they might have brought with them. It is too much to claim that they have abandoned those biases, but the key is that they have learned to get along. We have witnessed students develop strong relationships with one another that cross borders. This includes making connections with domestic students and members of the larger Kalamazoo community. The FSO officers participate in RSO leadership councils and have had the opportunity to learn about governance and student affairs, and individual students have joined other non-international RSOs. As Glass et. al. (2013) demonstrated, "leadership programs that involve collaboration and teamwork with others from varied cultural backgrounds has a markedly strong effect on international students' sense of community" (p. 13).

One of the key factors in the success of this community building, at both the university and FSO level, has been the fluidity by which student identities have been acknowledged. Students have had the opportunity to be seen as an international student from $\mathrm{x}$ or $\mathrm{y}$ country, but they have also been able to be seen as a student in x or y program, as a guitar player, as a baker, as a member of $\mathrm{x}$ or $\mathrm{y}$ tribe or ethnic group, as a former teacher, a banker, etc. This sounds trivial but if we reflect on the earlier discussion of identity, we know that this is a fluid concept. Too often when students are abroad their identity as an "international student" takes center stage and becomes the dominant thing that the university community sees about them. How often have we heard discussions around campus about "international students" that fail to take into consideration the vast differences that this seemingly benign administrative category entails? We want to avoid forcing upon students Maalouf's (2000) "one single affiliation" because a single identity is limiting. By creating a community that transcended one's national identity and citizenship, the students were able to find a sense of belonging that afforded a complex and fluid exercise of identity, which helped students 
make connections across seemingly fixed national boundaries. This allowed for connections to be made that transcended Maaloof's (2000) "murderous identities."

Cosmopolitanism has sometimes been accused of flattening identities. As Marianna Papastephanou (2002) writes, "the core assumption of most cosmopolitans from the Stoics to Rousseau, Montaigne and down to some contemporary liberals...is that cosmopolitan attitudes emanate from the realization of our common human nature" (p. 74). The global slate is wiped clean, in effect, allowing history to start anew on a level, global field. This is unrealistic and is ultimately doomed to failure because one cannot shed one's constitutive identities at will. Rather, a rooted cosmopolitanism, one where particular attachments are partially constitutive of identity, is what should be the aim. Membership in particular communities need not stand as an obstacle to engaging in respectful dialogue. The values one brings provide not a barrier or unbridgeable gap between cultures but a means by which dialogue can begin.

Our identities, and the ways in which we carry them out into a diverse and multicultural world, offer a starting point from which to engage. In paraphrasing Nussbaum (1996), we should

continue to regard [our]selves as defined partly by [our] particular loves-[our] families, [our] religious, ethnic, or racial communities, or even [our] country. But [we] must also, and centrally, learn to recognize humanity wherever [we] encounter it, undeterred by traits that are strange to [us], and be eager to understand humanity in all its strange guises. [We] must learn enough about the different to recognize common aims, aspirations, and values, and enough about these common ends to see how variously they are instantiated in the many cultures and their histories. (p. 9)

There is much to be gained from "teaching and learning in a culturally diverse environment" (Wächter, 2003; in Clifford et al., 2009, p. 2), because it opens up new possibilities for approaching challenges, problems, and even just quotidian existence. This article has offered a glimpse into the ways that we can support community building and the exploration of fluid identities for international students at the institutional level. None of the activities that were offered are particularly unique; rather, it is the fact of offering students the opportunity to gather and get to know one another that has helped to foster belonging. It affords international students a sense of belonging that helps them reach out to their fellow international and domestic peers. The presence of international students enriches the classroom and campus 
experience and helps get us closer to an attitude of cosmopolitanism. But it will not happen without effort on the part of the university and the part of the actors involved. Universities need to avoid reducing international students into a monolithic group defined by the simple fact of their citizenship. Instead, there needs to be effort to find common ground among students, to offer an environment which fosters belonging beyond national identity and instead allows the multiplicity and fluidity of identity that these students bring into play.

\section{REFERENCES}

Appiah, K. (2006). Cosmopolitanism: Ethics in a world of strangers. New York: W.W. Norton and Co.

Beck, U. (2006) Cosmopolitan vision. Cambridge: Polity.

Bureau of Education and Cultural Affairs, U.S. Department of State (n.d.). Retrieved from https://eca.state.gov/about-bureau

Clifford, V., Haigh, M., Henderson, J., \& Adetunji, H. (2009). Risky business: Negotiating new knowledge, new values, new behaviours. Paper presented at European Association of International Education, $21^{\text {st }}$ Annual Conference. Madrid, September 2009.

Chronicle of Higher Education. (2007). Top producers of Fulbright scholars and students 2016-17. Retrieved from https://www.chronicle.com/article/TopProducers-of-Fulbright/239220

Deardorff, D. (2010). From theory to practice: Intercultural competence (invited paper for NAFSA). Retrieved from http://www.nafsa.org//file//theory_ connections_intercultural_competence.pdf

Lee, J., \& Rice, C. (2007). Welcome to America? International student perceptions of discrimination. Higher Education, 53(3), 381-409.

Maalouf, A. (2000). In the name of identity. New York: Penguin.

Macready, C., \& Tucker, C. (2011) Who goes where and why? An overview and analysis of global educational mobility: New York: Institute of International Education.

Marston, S., Knox, P., \& Liverman, D. (2002). World regions in global context. Upper Saddle River, NJ: Pearson, Prentice Hall.

Nussbaum, M. (1994). Patriotism and cosmopolitanism. Boston Review, xix, 3-6.

Nussbaum, M (1996). For love of country: Debating the limits of patriotism. Boston: Beacon.

Papastephanou, M. (2002). Arrows not yet fired: Cultivating cosmopolitanism through education. Journal of Philosophy of Education, 36(1), 69-86.

Ritzer, G. (2010). Globalization: A basic text. Chichester, UK: Wiley-Blackwell.

Steger, M. (2003). Globalization: A very short introduction. Oxford: Oxford University Press.

Tervalon, M., \& Murray-Garcia, J. (1998). Cultural humility versus cultural competence: A critical distinction in defining physician training outcomes in multicultural education. Journal of Health Care for the Poor and Underserved, $9(2), 117-125$. 
Tuan, Y-F. (1977). Space and place: The perspective of experience. Minneapolis: University of Minnesota Press.

Wächter, B. (2003). An introduction: Internationalisation at home in context. Journal of Studies in International Education, 7(1), 5-11.

MICHELLE METRO-ROLAND, PhD, is Director of Faculty and Global Program Development at the Haenicke Institute for Global Education and Affiliate Professor of Geography at Western Michigan University. Her research explores landscape, place, and material culture, and the ways in which various scales of local, national, and global culture interact in the built environment. Email: michelle.metro-roland@wmich.edu

Manuscript submitted: November 30, 2017

Manuscript revised: March 14, 2018 Accepted for publication: April 1, 2018 